\title{
Growth Hormone Release Inhibiting Hormone in Acromegaly
}

\author{
G. M. BESSER, \\ C. H. MORTIMER \\ D. CARR, A. V. SCHALLY, \\ D. H. COY, \\ D. EVERED, \\ A. J. KASTIN, \\ W. M. G. TUNBRIDGE \\ M. O. THORNER, \\ R. HALL
}

tion in response to insulin-induced hypoglycaemia in normal men and was also effeotive in lowering circulating GH levels in the three acromegalic patients tested. Siler et al. (1973)

\section{Summary}

Growth hormone release inhibiting hormone (GHRIH) was administered by constant infusion over 75 minutes to eight acromegalic patients at different doses. 100 to $1,000 \mu \mathrm{g}$ were equally effective in reducing circulating growth hormone (GH) levels; $25 \mu \mathrm{g}$ lowered GH levels in only five patients, and at this dose the extent of the fall was smaller than from doses of $100 \mu \mathrm{g}$ or more. $10 \mu \mathrm{g}$ was ineffective. Injection of single doses of $500 \mu \mathrm{g}$ by intravenous, subcutaneous, and intramuscular routes caused only small and transient reductions in GH levels, though the effect was improved by injecting the hormone intramuscularly in $2 \mathrm{ml}$ of $16 \%$ gelatin. Injection of a suspension of $4 \mathrm{mg}$ GHRIH in $1 \mathrm{ml}$ of arachis oil lowered growth hormone levels for between three and four hours.

In four acromegalic patients an oral $50-g$ glucose tolerance test was performed during a continuous infusion of either saline or $1,000 \mu \mathrm{g}$ GHRIH. The "paradoxical" rise in growth hormone seen in these patients during the saline infusion was suppressed by GHRIH. The blood glucose responses were, moreover, modified by GHRIH in that the peak was delayed and occurred at the end of the infusion in each case. A "normal" glucose tolerance curve was converted to a "diabetic" type of response in two patients. This effect could be accounted for by the inhibition of insulin secretion known to occur with large doses of GHRIH.

We speculate that acromegaly may be primarily a hypothalmic disease due to deficiency of GHRIH resulting in excessive secretion of growth hormone from the pituitary and adenoma formation due to inappropriate and prolonged stimulation of the pituitary.

\section{Introduction}

We previously reponted the effects of the cyclic form of the synthetic tetradecapeptide growth hormone release inhibiting hormone (GHRIH), described by Brazeau et al. (1973), in normal subjects and in patients with acromegaly (Hall et al., 1973). An infusion of $500 \mu \mathrm{g}$ of that material over 75 minutes was found to inhibit pituitary growth hormone (GH) secre-

Medical Professorial Unit, St. Bartholomew's Hospital, London EC1A 7BE

G. M. BESSER, M.D., F.R.C.P., Senior Lecturer in Endocrinology

G. M. BESTIMER, M.B., M.R.C.P., Research Fellow

M. O. THORNER, M.B., M.R.C.P., Registrar

Department of Medicine, Royal Victoria Infirmary, Newcastle upon

Tyne NE1 4LP

D. CARR, M.B., M.R.C.P., Senior Registrar

D. EVERED, M.D., M.R.C.P., Research Fellow

D. EVER, M.P.

R. HALL, M.D., F.R.C.P., Professor of Medicine

Veterans Administration Hospital and Department of Medicine, Tulane University School of Medicine, New Orleans, Louisiana, U.S.A.

A. V. SCHALLY, PH.D., Professor of Medicine

A. H. COY, PH.D., Assistant Professor of Medicine

A. J. KASTIN, M.D., Associate Professor of Medicine also showed that GHRIH will inhibit GH secretion in normal subjects after the administration of arginine or levodopa.

The aim of this study was to establish the dose-response relationship between the inhibiting hormone and the reduction of GH levels in acromegaly with a view to defining the optimal dose for therapy. Preliminary observations were also made on the effects of GHRIH on blood sugar levels in view of the possible therapeutic value in those diseases associated with raised circulating levels of GH. Single-dose administration of GHRIH by differing routes and attempts to prolong the action of single doses are also reported.

\section{Patients and Methods}

Synthetic GHRIH prepared in the cyclic form and purified as described by Coy et al. (1973) was used in these studies.

Dose-response Study.-Eight acromegalic patients (six men and two women) aged 25 to 59 years volunteered to participate in the study, written consent being obtained in each case. All had radiological evidence of an enlarged pituitary fossa; five had received external irradiation to the pituitary, one had received external irradiation and an yttrium implant, and the other two were untreated. Each patient received $1,000,500,250$, and $100 \mu \mathrm{g}$ GHRIH on different occasions infused over 75 minutes in a single-blind, random cross-over design, so that each patient acted as his own control. After the initial studies it became apparent that $100 \mu \mathrm{g}$ GHRIH was as effective as $1,000 \mu \mathrm{g}$ in suppressing the release of $\mathrm{GH}$. The same subjects were therefore given $25-\mu \mathrm{g}$ and $10-\mu \mathrm{g}$ infusions over the same length of time three to four weeks after the first series of tests. In the first and second series of observations the expeniments were carried out at intervals of 24 to 48 hours. Samples for plasma GH assay were withdrawn from an indwelling venous cannula (insented $\mathbf{3 0}$ minutes earlier) 15 minutes before and then at intervals for 150 minutes after the stant of the infusion. GHRIH was given in $50 \mathrm{ml}$ of $0.9 \% \mathrm{NaCl}$ by means of a constant infusion pump. Plasma was separated immediately and stored at $-20^{\circ} \mathrm{C}$ until assayed. Samples taken from each patient during the infusions of 100 to $1,000 \mu \mathrm{g}$ and 10 and $25 \mu \mathrm{g}$ were measured in the same assay.

Effects of Differing Routes of Administration and Delayedrelease Preparations.-A 59-year-old woman with acromegaly (case 3) had an indwelling venous cannula inserted 45 minutes before receiving single injections of $500 \mu \mathrm{g}$ GHRIH. These were given on separate occasions intravenously, subcutaneously, and intramuscularly. Blood was sampled 15 minutes before each injection, at zero time, and at intervals for $\mathbf{2 4 0}$ minutes thereafter. The intramuscular injection was later repeated with $500 \mu \mathrm{g}$ GHRIH suspended in $2 \mathrm{ml}$ of warm $16 \%$ gelatin. Tests were performed on successive days and all samples were assayed in the same batch. A man aged 38 with acromegaly (case 5) received an intramuscular injection of $4 \mathrm{mg}$ GHRIH suspended in arachis oil. Blood samples were withdrawn at intervals over the next 30 hours.

Effect of Infusion of GHRIH on GH and Blood Glucose Response during Oral Glucose Tolerance Tests.-Four acromegalic patients (three women and one man aged 49-59 years) 
without clinical or chemical diabetes mellitus but who were known to show "paradoxical" GH rises in response to oral glucose loading were studied on two occasions after the ingestion of glucose. All patients were recumbent and at rest for 30 minutes before and during the study. Blood samples were withdrawn via an indwelling intravenous cannula before the administration of $50 \mathrm{~g}$ glucose and at 30-minute intervals thereafter for 150 minutes. During this time each patient received an infusion of either $50 \mathrm{ml} 0.9 \% \mathrm{NaCl}$ or $1,000 \mu \mathrm{g}$ GHRIH in the same volume of saline. The specimens from each patient were assayed in the same batch.

Assays. - Plasma GH was measured by a double antibody radioimmunoassay and the results were expressed in $\mathrm{ng}$ of M.R.C. standard $69 / 46$ per $\mathrm{ml}$. This standand was also used for iodination. The maximum coefficient of variation between assays was $15 \%$. Blood glucose was measured by a neocuprine method (Technicon).

\section{Results}

Dose-response Study.-When the effects of differing doses of GHRIH on circulating GH levels were compared it was seen that there was no significant difference between 1,000 , 500,250 , and $100 \mu \mathrm{g}$ given over 75 minutes (fig. 1). The individual responses to $500 \mu \mathrm{g}$ are shown in fig. 2. The $\mathrm{GH}$ rebound phenomenon after the end of the injection, reported previously, was again shown. When the dose was reduced to $25 \mu \mathrm{g}$, however, plasma GH levels fell in only five of the eight patients, but the extent of the fall was not as great as when $100 \mu \mathrm{g}$ was used. In the five responsive patients $\mathrm{GH}$ levels fell from basal levels of $60,60,14,22$, and $23 \mathrm{ng} / \mathrm{ml}$ to $34,21,8,19$, and $14 \mathrm{ng} / \mathrm{ml}$ respectively at the end of the infusions. None of the eight subjects showed a reduction in circulating GH levels in response to $10 \mu \mathrm{g}$ GHRIH.

Effects of Differing Routes of Administration and Delayedrelease Preparations.-The duration of action of the single

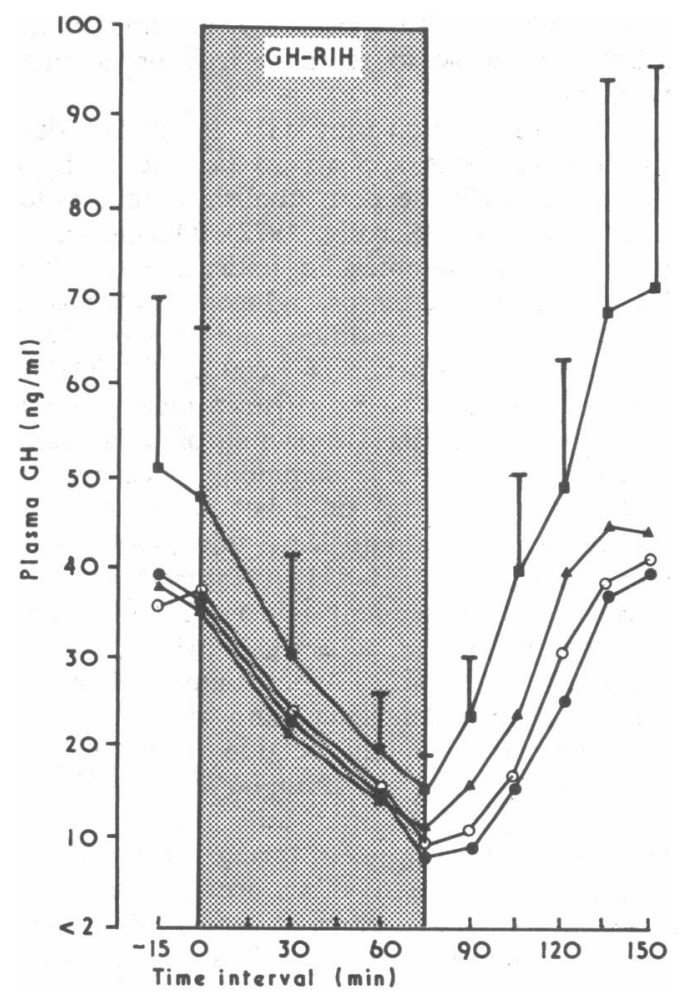

FIG. 1-Mean plasma GH levels in eight acromegalic patients during 75-minute infusions of graduated doses of GHRIH $(\square=100 \mathrm{\mu g}$. $250 \mu \mathrm{g}$. $\Delta=500 \mu \mathrm{g}$. $O=1,000 \mu \mathrm{g}$.) For the $100-\mu \mathrm{g}$ dose mean levels are shown +1 S.E.

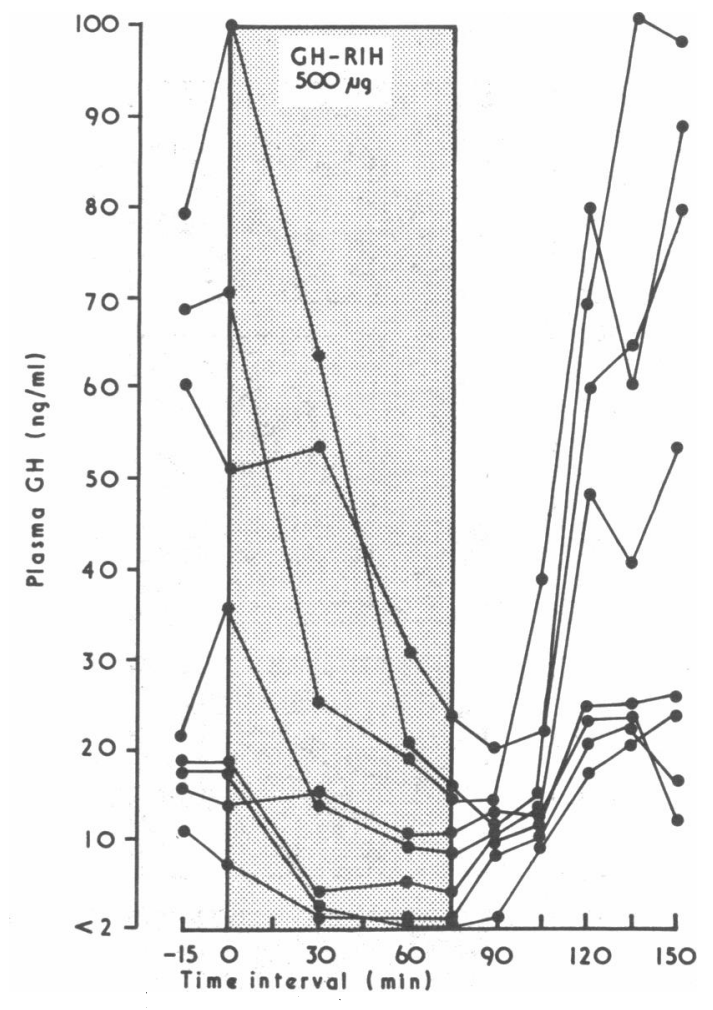

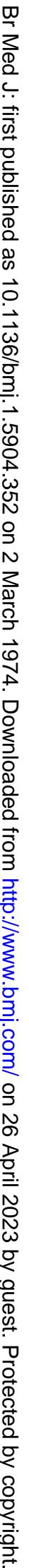

injections of $500 \mu \mathrm{g}$ GHRIH by any route was one to two hours (table I). When $500 \mu \mathrm{g}$ was injected with gelatin the time course of action was similar (two hours) though circulating GH levels were reduced to a minimum of $16 \mathrm{ng} / \mathrm{ml}$ compared with 22 to $24 \mathrm{ng} / \mathrm{ml}$ when GHRIH was injected alone by the other routes. The suspension of $4 \mathrm{mg}$ GHRIH in arachis oil given by intramuscular injection (table II) resulted in a reduction of $\mathrm{GH}$ levels for three to four hours.

TABLB I-Case 3. Plasma GH Levels (ng/ml) in Response to $500 \mu g$ GHRIH injected Intravenously, Subcutaneously, and Intramuscularly

\begin{tabular}{|c|c|c|c|c|c|c|c|c|c|c|c|c|}
\hline \multirow{2}{*}{$\begin{array}{l}\text { Route of GHRIH } \\
\text { Administration }\end{array}$} & \multicolumn{12}{|c|}{ Time Interval (Minutes): } \\
\hline & -15 & 0 & 15 & 30 & 45 & 60 & 90 & 120 & 150 & 180 & 210 & 240 \\
\hline $\begin{array}{l}\text { Intravenous } \\
\text { Subcutaneous } \\
\text { Intramuscular } \\
\text { Intramuscular in } \\
16 \% \text { gelatin }\end{array}$ & $\begin{array}{l}34 \\
35 \\
25 \\
29\end{array}$ & $\begin{array}{l}29 \\
30 \\
24 \\
29\end{array}$ & $\begin{array}{l}27 \\
29 \\
25 \\
27\end{array}$ & $\begin{array}{l}25 \\
26 \\
22 \\
20\end{array}$ & $\begin{array}{l}24 \\
23 \\
24 \\
16\end{array}$ & $\begin{array}{l}24 \\
23 \\
24 \\
17\end{array}$ & $\begin{array}{l}26 \\
35 \\
28 \\
20\end{array}$ & $\begin{array}{l}28 \\
41 \\
47 \\
26\end{array}$ & $\begin{array}{l}27 \\
44 \\
42 \\
35\end{array}$ & $\begin{array}{l}30 \\
32 \\
58 \\
24\end{array}$ & $\begin{array}{l}29 \\
30 \\
42 \\
27\end{array}$ & $\begin{array}{l}27 \\
31 \\
48 \\
35\end{array}$ \\
\hline
\end{tabular}

TABLE II-Case 5. GH Levels in Response to Intramuscular Injection of $4 \mathrm{mg}$ GHRIH suspended in Arachis Oil

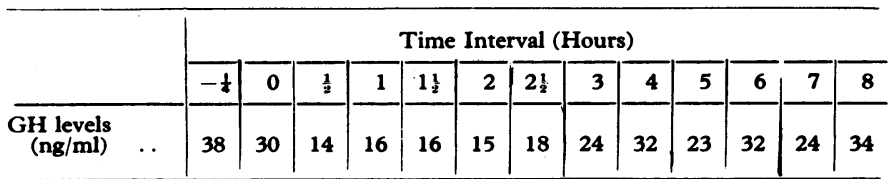

From 9 to 23 hours GH levels remained between 24 and $35 \mathrm{ng} / \mathrm{ml}$, and at 24 and 30 hours the level was $13 \mathrm{ng} / \mathrm{ml}$.

Effect of Infusion of GHRIH on GH and Blood Glucose Responses during Oral Glucose Tolerance Tests.-When the levels of GH were measured during the normal saline infusion after a 50-g oral glucose load each patient showed an increase in circulating $\mathrm{GH}$ levels instead of the suppression seen in normal subjects- that is, there was a "paradoxical" rise (fig. 3). When glucose loading was accompanied by the 


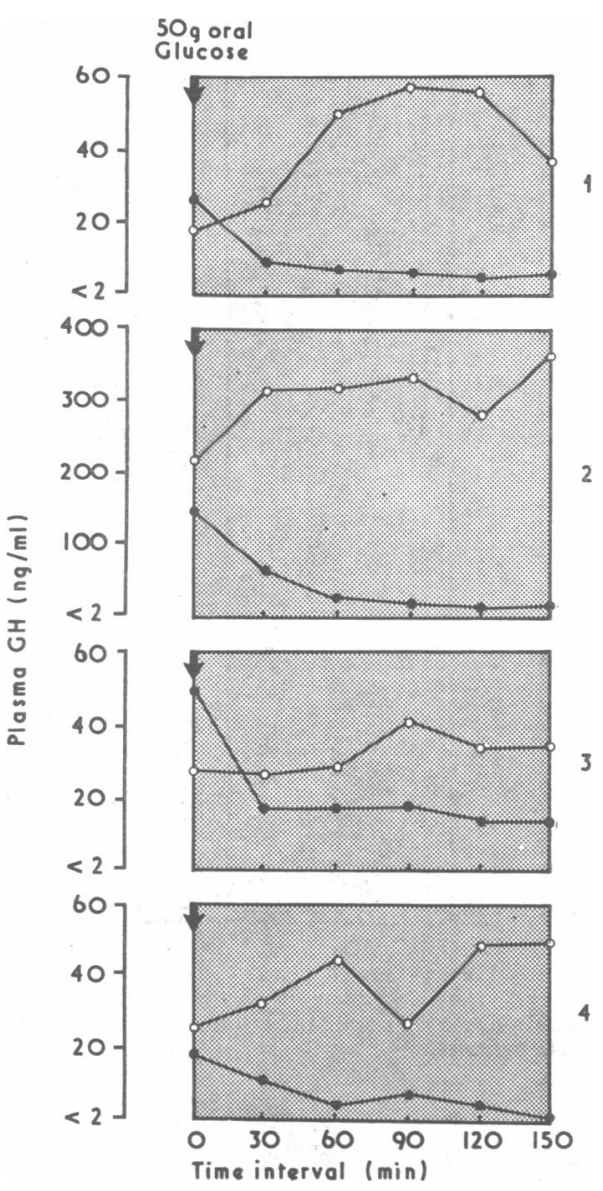

FIG. 3-Cases 1 to 4 . $\mathrm{GH}$ levels after $50 \mathrm{~g}$ oral glucose load while receiving infusions of normal saline (O-O) GHRIH $1,000 \mu \mathrm{g}($

infusion of $1,000 \mu \mathrm{g}$ GHRIH over 150 minutes instead of saline the paradoxical rise was prevented and the GH levels were lowered. Study of the effects on blood glucose levels (fig. 4) showed that a normal glucose response was obtained in each patient during the control saline infusion, with peak levels at between 30 and 90 minutes. When the glucose tolerance test was repeated during an infusion of GHRIH the results were noticeably different. In cases 2 and 3 there was an initial fall in blood glucose and all four patients showed a delayed rise, so that the maximum level was reached at 150 minutes. Two patients (cases 1 and 4) now had a diabetic type of response, with blood glucose levels of 245 and $165 \mathrm{mg} /$ $100 \mathrm{ml} 120$ minutes.

\section{Discussion}

Since the characterization and subsequent synthesis of GHRIH it has been suggested that this cyclic tetradecapeptide may be of use in the treatment of conditions associated with increased circulating levels of $\mathrm{GH}$, such as acromegaly and diabetes mellitus (Hall et al., 1973; Prange Hansen et al., 1973). It was necessary, therefore, to determine the optimum dose which would result in satisfactory inhibition of pituitary GH secretion in acromegalic patients. From our studies doses of 100 to $1,000 \mu \mathrm{g}$ infused over 75 minutes appeared to be equally effective but a dose of $25 \mu \mathrm{g}$ was not associated with a consistent response. A dose of $10 \mu \mathrm{g}$ administered over the same period of time did not produce a significant decrease in GH in any patient. Thus the minimum therapeutic dose for use in acromegaly seems to be in the region of $1.3 \mu \mathrm{g}$ GHRIH per minute, equivalent to $100 \mu \mathrm{g}$ infused over 75 minutes.

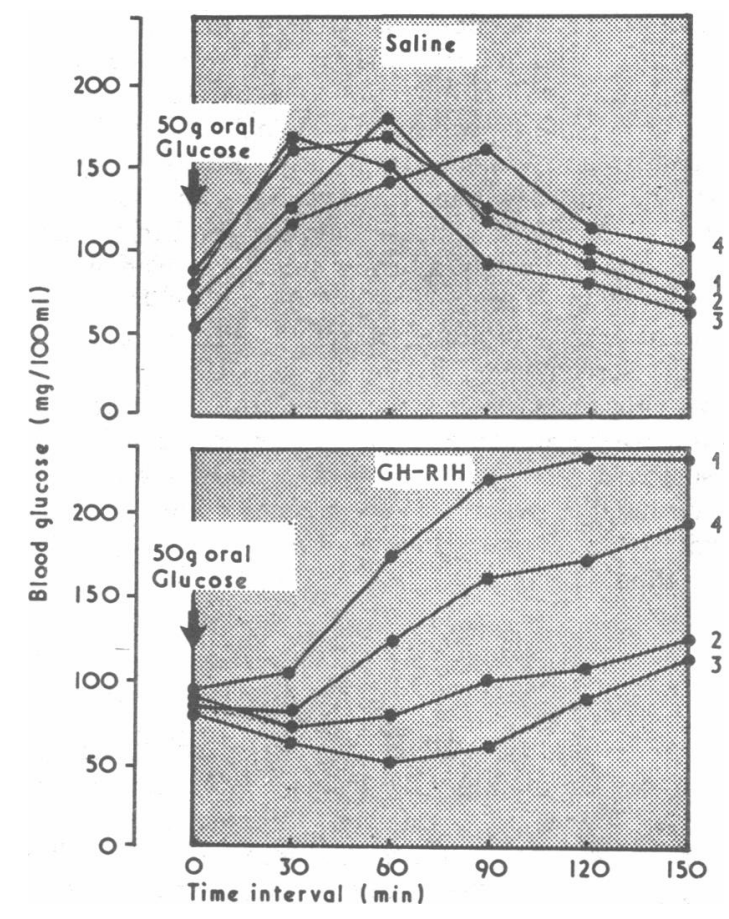

FIG. 4-Cases 1 to 4. Blood glucose responses to 50-g oral glucose load while receiving infusions of normal saline and GHRIH $1,000 \mu \mathrm{g}$.

Injection of a single dose of $500 \mu \mathrm{g}$ GHRIH by intravenous, subcutaneous, and intramuscular routes caused only slight and transient suppression of GH levels. Though the suspension of $4 \mathrm{mg}$ of the material in arachis oil resulted in a more sustained inhibition of pituitary GH secretion (between three and four hours) the limited duration of action achieved was clearly insufficient for effective therapy. It remains to be seen whether incorporation of GHRIH with other repository media, to produce "depot" preparations, will be of any greater value. The possibility of synthesizing analogues of GHRIH less susceptible to rapid destruction in vivo is also being investigated.

In normal subjects circulating $\mathrm{GH}$ levels fall during oral glucose loading and this appears to be due to hypothalmic influences, since stalk section abolishes the influence of hyperglycaemia on GH (Schally, 1972). During these studies we investigated four acromegalic patients who showed the paradoxical rise in $\mathrm{GH}$ after oral glucose, well recognized as a common feature of the condition, and showed that this rise was suppressed by the infusion of $1,000 \mu \mathrm{g}$ GHRIH. It seems possible that in normal subjeots a rise in blood glucose stimulates the secretion of GHRIH to switch off GH secretion and that the paradoxical GH rise commonly seen in acromegaly during oral glucose loading could be due to a deficiency of GHRIH secretion. This would leave unopposed the action of GH-releasing hormone (GH-RH) presumed to be secreted in response to the subsequent fall in blood glucose. It is tempting to speculate that acromegaly might be a pituitary manifestation of a primarily hypothalamic disease resulting from isolated FHRIH deficiency, and that the development of the pituitary tumour might be due to prolonged and inappropriate stimulation of the pituitary by GH-RH. Pituitary tumours in acromegaly are often still under some degree of hypothalmic control, since in many cases the glucosesensing mechanisms located there are still able to modify pituitary secretion of $\mathrm{GH}$ following changes in blood glucose. The possibility, however, that primary hypersecretion of GH-RH causes acromegaly cannot be excluded. Though these possibilities are intriguing clearly full evaluation of $\mathbf{G H}$ secretion can be made only when sensitive assays for GHRIH and GH-RH become available. The occasional occurrence of 
some suppression of $\mathrm{GH}$ levels by a rise in blood glucose in acromegalic patients suggests that there might be only a partial deficiency of GHRIH or partially suppressible GH-RH in these patients.

The infusion of GHRIH resulted in impairment of glucose tolerance and a change in the shape of the blood glucose curve despite the marked reduction in $\mathrm{GH}$ levels. This can be explained by the observations that GHRIH impairs insulin secretion in response to glucose by a direct aotion on the pancreas, as reported in normal subjects by Alberti et al. (1973). We have also carried out further studies which confirm this effect. Possibly the reduotion in insulin response to glucose and the impairment of secretion of thyroid-stimulating hormone after giving thyrotrophin releasing hormone (Hall et al., 1973) represent non-physiological responses to the large doses of GHRIH delivered to the general circulation. Clearly, however, they may have impontant implications if this hypothalamic hormone is to be used to treat diseases associated with excessive GH secretion. The production of impaired glucose tolerance curves in two patients by GHRIH and a rise in the blood glucose levels at 150 minutes in the other two suggest that the effects of the polypeptide with respect to pancreatic function and the gastrointestinal hormones need to be fully evaluated.

We wish to thank the nursing and technical staff of the Programmed Investigation Unit, Newcastle Royal Victoria Infirmary, and the metabolic ward, St. Bartholomew's Hospital, for their valuable help. The studies have been generously supported by the Joint Research Board of St. Bartholomew's Hospital and the Peel Medical Research Trust.

\section{References}

Alberta, K. G. M. M., et al. (1973). Lancet, 2, 1299.

Brazeau, P., et al. (1973). Science, 179, 77.

Coy, D. H., Coy, E. J., Arimura, A., and Schally, A. V. (1973). Biochemical and Biophysical Research Communications, 54, 1267.

Hall, R., et al. (1973). Lancet, 2, 581 .

Prange Hansen, Aa., Orskov, H., Seyer-Hansen, K., and Lundbaek, K. (1973). British Medical fournal, 3, 523 .

Schally, A. V. (1972). In The Hypothalamus and Pituitary in Health and Disease, ed. W. Locke and A. V. Schally, p. 242. Springfield, Illinois, Thomas. Siler, T. M., et al. (1973). Fournal of Clinical Endocrinology and Metabolism,
37, 632.

\title{
Management of Patients with Urinary Calculi
}

\author{
S. J. A. POWIS， J. BLACK， J. A. MACDOUGALL， J. W. CLEWS
}

British Medical fournal, 1974, 1, 355-357

\section{Summary}

A retrospective survey was made of 305 patients with proved urinary calculi. When those patients with a solitary stone were compared with those with multiple stones no diagnostically helpful difference was noted in the prevalence of abnormal serum or urine biochemistry, urinary infection, or anatomical abnormality of the urinary tract. The same was true of the stone composition and the need for surgery. It seems that neither routine radiological examination nor regular follow-up is likely to help identify patients whose stones are going to recur.

\section{Introduction}

Figures given for the prevalence of urinary calculi vary with the type of survey carried out. Ahlgren and Lorsted (1965), who studied all social groups in a large geographical area, reported the presence of urinary calculi in 80 per 100,000 of the population, whereas Larsen and Philip (1962), in a survey of Danish doctors, found a prevalence rate of 8,719 per 100,000 . However, the overall frequency of urinary stones, and hence the work load on stone clinics, does seem to be increasing.

The frequency of recurrence is also variable, some authors finding that $85-90 \%$ of patients suffer from solitary stones (Baker and Connolly, 1956; Garvey and Boyce, 1956); whereas Williams (1968) reported that $75 \%$ of patients with a urinary stone will form another.

Royal Hospital, Wolverhampton

S. J. A. POWIS, F.R.C.s., Senior Surgical Registrar, (Now Lecturer in Surgery, University of Birmingham)

J. BLACK, F.R.C.s., Surgical Registrar

J. A. MACDOUGALL, M.CHIR., F.R.c.s., Consultant Surgeon

J. W. CLEWS, M.B.CH.B., Clinical Assistant
The present survey attempted to define objective criteria whereby patients likely to suffer recurrent calculi could be identified. Radiological examination is commonly used as a routine check in stone clincs to deteot unexpected stone formation which may require intervention or further investigation. The value of such examinations has not been clearly shown.

\section{Patients and Methods}

A total of 305 patients were included in the survey, which was carried out retrospectively. All the patients had passed a stone or had unequivocal radiological evidence of a urinary calculus and had presented in the 10-year period 1962-71. During the period of this survey no patient was discharged from the clinic and the default rate was less than $2 \%$.

Biochemical investigation of urine and serum is now performed on all patients, though early in the series this was not always done on patients with solitary stones. Serum urea and electrolytes, calcium (three non-occluded venous samples) uric acid, creatinine, and plasma proteins were estimated. Urinary calcium excretion was assessed on three consecutive days on the routine ward diet. Normal ranges were: serum calcium 8.5 to $10.5 \mathrm{mg} / 100 \mathrm{ml}$; urine calcium below $300 \mathrm{mg} / 24$ hours. Urine was examined bacteriologically in all cases at the time of presentation and any infection was treated with antibiotics indicated by culture. Intravenous pyelography was performed on presentation to establish the exact site of the stones and also to detect anatomical abnormalities of the urinary traot. All available stones passed or removed surgically were analysed qualitatively.

Outpatient visits were at three- to 18 -month intervals depending on the presence or absence of symptoms, their duration, and the site of the stones. At each visit a clinical appraisal of the symptoms was made and either a plain $x$ ray film or an intravenous pyelogram was taken. The value of these investigations was assessed by estimating the number of clinically unexpected findings and the treatment indicated by these. 